Gut, 1974, 15, 728-732

\title{
Luminal distension as a possible consequence of experimental intestinal perfusion
}

\author{
DAVID WINGATE ${ }^{1}$, ASHLEY HYAMS, AND SIDNEY PHILLIPS
}

From the Gastroenterology Research Unit, Mayo Clinic, Rochester, Minnesota, USA, the Department of Physiology, and the Computer Section, London Hospital Medical College, London, England

SUMMARY In an experimental jejunal perfusion study, distress in healthy subjects occurred during eight out of 16 perfusions in which intestinal secretion was provoked. Calculation demonstrates the volumetric consequences of inadequate recovery of secretory perfusates, and analysis of the perfusion studies shows that distress was significantly associated with poor recovery of the perfusate. These observations are pertinent to increasing interest in the phenomenon of intestinal fluid secretion.

The development of intestinal intubation techniques since the work of Abbott and Miller (1936) has allowed extensive study of intestinal absorption in man. Until recent years, such perfusion studies have usually involved the perfusion of physiological electrolytes or nutrients into the intestine (Fordtran and Ingelfinger, 1968), and hazards associated with such perfusions have been rarely reported. Even the use of balloons obstructing the lumen of the intestine seems to be a safe procedure except in the presence of intestinal disease (Schmid, Phillips, and Summerskill, 1968) although pancreatic duct obstruction by the balloon has occurred (J. R. Malagelada, personal communication). Recently, there has been interest in the perfusion of solutes which, at low concentrations, inhibit intestinal water absorption or provoke intestinal water secretion; such substances include laxatives, hydroxy fatty acids, and bile acids. In a recent study of the effect of glycine-conjugated bile acids on jejunal absorption in man (Wingate, Phillips, and Hofmann, 1973), it was briefly reported that perfusions of bile acids which induced net secretion were in some cases associated with unpleasant symptoms in healthy subjects. However, further instances of adverse effects from perfusions with bile acids (E. Krag and S. F. Phillips, personal communication), bisacodyl (P. Czybylski and K. Ewe, personal communication) and prostaglandins (C. Matuchansky, personal communication) have come to our attention, suggesting that this phenomenon is likely to occur in the presence of secretory perfusions.

${ }^{1}$ Requests for reprints to: Dr D. L. Wingate, London Hospital Medical College, Turner Street, London, E1 2AD.

Received for publication 21 May 1974.
The introduction of a physiological fluid (perfusate) into the intestinal lumen is implicit in perfusion studies, as is the subsequent sampling of the luminal contents. This sampling, commonly by siphonage, rarely (if ever) allows total recovery of the perfusate. With solutions which will be absorbed, incomplete recovery may be of no consequence, but this may not be true for studies in which net fluid secretion into the intestinal lumen is provoked, especially when the secretogenic agent is a solute in the perfusate. We are not aware of any previous quantitative analysis of the consequence of incomplete perfusate recovery. The clinical effects of the perfusions reported here were associated with poor recovery of secretogenic perfusates, and calculation supports the hypothesis that these phenomena were causally related.

\section{Methods}

Proximal jejunal segments of healthy adult volunteers who had given informed consent were perfused with glucose electrolyte solutions containing $0,2 \cdot 5$, 5.0 , or $10.0 \mathrm{mM} / 1$ concentrations of glycine-conjugated bile acids, by a double-lumen technique (Phillips and Summerskill, 1968). A detailed account of the solutions and methods employed has been given elsewhere (Wingate et $a l, 1973$ ). Each subject received four consecutive 90-minute perfusions, each perfusion containing one of the bile acid concentrations in a sequence determined by a Latin square design. The bile acids employed were glycocholic acid (GC), glycochenodeoxycholic acid (GCDC), and glycodeoxycholic acid (GDC). 


\begin{tabular}{llrr}
\hline Concentration of Bile Acid $(\mathrm{mM})$ & $G C(-S E M)$ & $G C D C$ & $G D C$ \\
\hline 0 (control) & $2 \cdot 1 \pm 0.1$ & $1.8 \pm 0.3$ & $2 \cdot 0 \pm 0.4$ \\
25 & $1.9 \pm 0.4$ & $1.2 \pm 0.2$ & $1 \cdot 1 \pm 0.2$ \\
5.0 & $2 \cdot 0 \pm 0.5$ & $0.2 \pm 0.2$ & $-0.8 \pm 0.2$ \\
10.0 & $1 \cdot 7 \pm 0.1$ & $-1.3 \pm 0.1$ & $-2.3 \pm 0.4$ \\
\hline
\end{tabular}

Table I Net water movement during jejunal perfusion with different concentrations of glycine-conjugated bile acids ${ }^{1}$ ${ }^{1}$ Water movement expressed as $\mathrm{ml} / \mathrm{min}$ absorbed ( + ve) or secreted ( - ve) in $25 \mathrm{~cm}$ segment of jejunum. Each value is mean $\pm \mathrm{SEM}$ of perfusion in four subjects.

\section{NET WATER MOVEMENT}

Distal sampling from the perfusion system was collected and the collections were divided into 10minute aliquots. The perfusate contained polyethylene glycol (PEG) labelled with 14-carbon as a volume indicator and the change in isotope concentration between perfusate and aspirate was used to calculate the change in volume in the perfused segment (Wingate, Sandberg, and Phillips, 1972). The values taken for net water movement were for the last four 10-minute periods in each perfusion when it was assumed that steady state conditions had been achieved.

\section{PERCENTAGE RECOVERY}

The percentage recovery of the perfusate was obtained by expressing the volume recovered by distal sampling as a percentage of the volume perfused over the same 10 -minute period. The mean percentage recovery for each perfusion was calculated for the entire 90 -minute period of each perfusion.

\section{Results}

\section{NET WATER MOVEMENT}

The changes in net water movement induced by the different concentrations of glycine-conjugated bile acids are shown in table $I$. The trihydroxy bile acid GC had little effect on net water movement but both GDC and GCDC induced secretion or arrested absorption at 5 and $10 \mathrm{mM} / 1$ concentrations.

\section{ADVERSE EFFECTS}

Adverse effects were malaise, vomiting, nonspecific abdominal pain, and diarrhoea. These occurred only during perfusion with 5 and $10 \mathrm{mM} / 1$ dihydroxy bile acids, and their distribution in these perfusions is shown in table II. In two of the perfusions, the adverse effects were severe enough to compel medication (pethidine intramuscularly) and the termination of the perfusion before the end of the 90-minute period. All adverse effects were rapidly relieved within a few minutes of replacing the bile-acid perfusate with a control (bile acid-free) solution.

\begin{tabular}{llll}
\hline & Subject & \multicolumn{2}{l}{ Toxic Sign with } \\
\cline { 2 - 4 } & & $5 \cdot 0 \mathrm{mM}$ & $10 \cdot 0 \mathrm{mM}$ \\
\hline $\begin{array}{l}\text { Glycochenodeoxy- } \\
\text { cholic }\end{array}$ & 1 & $\overline{\text { Vomiting, pain }}$ & $\begin{array}{l}\text { Vomiting, } \\
\text { abdominal pain }\end{array}$ \\
& 2 & $\overline{\text { Vomiting, }}$ & $\begin{array}{l}\text { Vomiting, } \\
\text { abdominal pain }\end{array}$ \\
& 4 & Vomiting & $\begin{array}{l}\text { Vomiting } \\
\text { Glycodeoxycholic }\end{array}$ \\
& 1 & - & $\begin{array}{l}\text { Abdominal pain, } \\
\text { diarroea }\end{array}$ \\
& 2 & - & $\overline{\text { Abdominal pain }}$ \\
\hline
\end{tabular}

Table II Toxicity of glycine-conjugated bile acids

${ }^{1}$ Required medication

Since adverse effects only occurred with dihydroxy bile acid concentrations which arrested absorption or provoked net secretion, it was assumed that subjects who experienced discomfort would show greater net secretion rates. In fact, within experimental groups, there was no correlation between the magnitude of net secretion and the occurrence of adverse effects. It was this latter finding that prompted scrutiny of the variation in recovery of perfusates.

\section{PERCENTAGE RECOVERY OF PERFUSATES}

Percentage recoveries for perfusions of dihydroxy bile acids in concentrations associated with adverse effects were calculated, and some significant differences were found between 'toxic' and 'non-toxic' perfusions. These are shown in table III. In this context, 'toxic' merely denotes the association of adverse effects with a perfusion.

A significant difference $(P<0.02)$ was found between recoveries of toxic and non-toxic perfusates. The data provide an explanation for the otherwise baffling phenomenon of toxicity with GCDC perfusates, when, as shown in table $I$, the effect of GCDC on absorption is less than that of GDC. Recovery of GCDC perfusates was, overall, significantly less than recovery of GDC perfusates. It is also clear that when toxicity was associated with 5 $\mathrm{mM} / 1$ perfusates (in three perfusions) recovery was very poor. 


\begin{tabular}{llll}
\hline Perfusion & No. & Percentage Recovery & $\begin{array}{l}\text { Significance }(p) \text { of Difference } \\
\text { between Pairs }\end{array}$ \\
\hline All toxic & 8 & $35 \pm 5$ & $<0.02$ \\
All non-toxic & 8 & $56 \pm 6$ & $<0.02$ \\
All toxic 5 mM & 3 & $27 \pm 9$ & $<0.01$ \\
All non-toxic 5 mM & 5 & $62 \pm 6$ & $<0.05$ \\
All toxic GDC & 4 & $40 \pm 5$ & $<0.01$ \\
All non-toxic GDC & 4 & $36 \pm 5$ & $<$ \\
All GCDC & 8 & $55 \pm 5$ & \\
All GDC & 8 & $42 \pm 6$ & \\
All non-toxic GCDC & 4 & $70 \pm 4$ & \\
All non-toxic GDC & 4 & & \\
\hline
\end{tabular}

Table III Percentage recovery of 'toxic' perfusion fluids'

ISixteen perfusions of glucose-electrolyte solutions containing $5 \mathrm{mM} / 1$ or $10 \mathrm{mM} / 1$ glycochenodeoxycholate (GCDC) or glycodeoxycholate (GDC). Percentage recovery $=100 \times$ volume recovered/volume perfused. Results are expressed as means \pm SEM, and significance of differences calculated using non-paired $t$ tests.

The cause of poor recovery was obvious during the conduct of the experiment. Five and $10 \mathrm{mM} / 1$ dihydroxy bile acid perfusions provoked considerable secretion of mucus, and this mucus caused intermittent obstruction of the siphonage tube. Even continuous vigilance by the experimenters did not always solve the problem, since flow from the siphonage tube is intermittent even when the lumen of the tube is unobstructed.

\section{BILE ACID ABSORPTION}

Bile acid absorption was minimal, being less than $5 \%$ of the quantity perfused in the absence of net fluid absorption (Wingate et al, 1973).

\section{Discussion}

The cause of the distress induced by dihydroxy bile acid perfusion in healthy subjects was at first obscure. Intraluminal conjugated bile acids are not recognized as a source of abdominal distress, and higher concentrations than those employed here may be found in the normal human intestinal lumen after gallbladder contraction. Reported effects in vitro of bile acids on enterocyte enzyme systems (Pope, Parkinson, and Olson, 1966; Hepner and Hofmann, 1973) do not appear to be of clinical significance. The symptoms experienced by the subjects were not sufficiently specific to indicate a precise pathophysiological origin. Since it was noted that symptoms were only associated with perfusates which either arrested net absorption or induced frank secretion, this prompted an analysis of the volume changes involved.

When a perfusate containing a non-absorbed secretogenic solute is used as a test solution in an intestinal perfusion system, and only partly recovered by siphonage at the end of the test segment, the residual solute will continue to induce secretion distal to the test segment. This distal secretion will continue until the solute is either diluted to a concentration $\left(C^{\prime}\right)$ which does not provoke secretion, or removed from the lumen. The extreme case is shown by simple calculation. The data summarized in table I yield the information that $C^{\prime}$ for GDC is $4.3 \mathrm{mM} / 1$. If $10 \mathrm{ml} / \mathrm{min}$ of a $10 \mathrm{mM} / 1$ solution of $G D C$ is perfused into the intestine, and the GDC is neither absorbed nor inactivated, the volume will increase until $23 \mathrm{ml} / \mathrm{min}$ will pass a point distal to the perfusion point. The assumption underlying perfusion techniques is that distal recovery of the perfusate will prevent this volume expansion. The quantitative consequence of recovering less than $100 \%$ of a secretogenic perfusate is illustrated in figure 1 . In unit time, a volume $V_{i n}$ is perfused into the intestinal

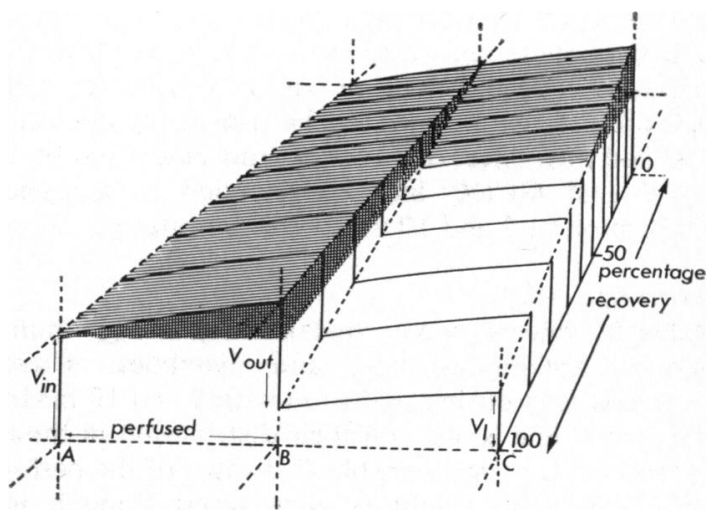

Fig 1 Volume changes in the perfusion segment $(A B)$ and the adjacent distal segment $(B C)$ during perfusion of a secretogenic solution into the lumen at $A$, showing the dependence of the residual volume $\left(V_{1}\right)$ at $C$ on the proportion of fluid removed at $B$. Shading indicates volumes exceeding the volume perfused at $A\left(V_{i n}\right)$. 
lumen at point $A$, and a volume $V_{\text {out }}$ is removed by siphonage at point $\mathrm{B}$. AB is the perfusion segment, and $B C$ is the adjacent distal segment, equal in length to $A B . V_{1}$ is the residual volume which passes point $C$ in unit time. Assuming steady state conditions, the percentage recovery (cf table III) is $R$, where

$$
\mathbf{R}=\frac{\mathbf{V}_{\text {out }}}{\mathbf{V}_{\text {in }}} \times 100 \ldots \ldots \ldots \ldots \ldots \text { (1) }
$$

Figure I shows that in the presence of secretion, even when $R=100 \%$, there is residual perfusate which will increase in volume in segment $\mathrm{BC}$, and as $R$ falls, $V_{1}$ increases and exceeds $V_{\text {in }}$.

For comparison, fig 2 illustrates the same perfusion geometry during absorption; in this case, no perfusate will reach $C$ until $R$ falls well below $100 \%$. In this instance, the rate of volume change in $\mathrm{AB}$ and $\mathrm{BC}$ is constant; the problem of computing volume change in the presence of a secretogenic solute is that this is being constantly modified by dilution of the solute, and calculation of $V_{1}$ must take account of this by solving differential equations for volume changes between $\mathrm{AB}$ and $\mathrm{BC}$.

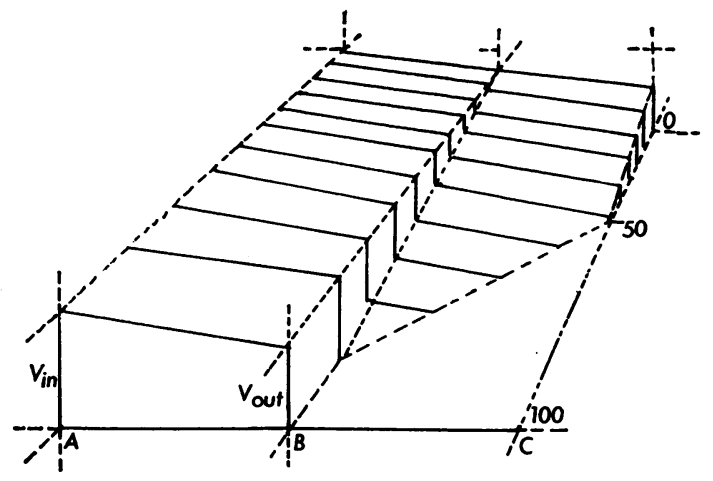

Fig 2 Volume changes in the perfusion segment $(A B)$ and the adjacent distal segment $(B C)$ during perfusion at $A$ of a solution which is absorbed.

Even if our hypothesis is correct, some questions remain to be answered. Since intestinal perfusion is not a new technique, why should fluid distension be a 'new' phenomenon? It is possible that adverse effects of perfusion have occurred in the past, but have been attributed to idiosyncrasy or intolerance of intubation. A more probable explanation is to be found in the fact that the experimental use of perfusates containing secretogenic substances in human small intestine is a recent development. Allied to this, there has been an increasing tendency to perfuse the small intestine with a double-lumen system with an occlusive balloon (Phillips and Summerskill, 1966) rather than with a triple-lumen system with a mixing segment (Whalen, Harris, Geenan, and Soergel, 1966). The controversy over the respective merits of the two systems has concentrated on their accuracy in measuring absorption (Sladen and Dawson, 1968; Fordtran, 1969; Sladen and Dawson, 1970; Modigliani and Bernier, 1971). One difference between the two systems which has not so far received attention, probably because it was thought to be of little or no interest, is that the triple-lumen system has two siphonage tubes, compared to the single siphonage of the double-lumen system. It may be for this reason that Russell and his colleagues (Russell, Allan, Gerskowitch, and Cochran, 1973) apparently did not encounter adverse effects with bile acid perfusions similar to ours, since they combined the use of an occlusive balloon with a mixing segment and a triple-lumen perfusion system.

What significance should be attached to our findings? Our model demonstrates that secretogenic perfusions may generate substantial volumes of fluid in the lumen of the small intestine. Our hypothesis suggests that such volumes can cause discomfort in healthy subjects and also raises the possibility of hazard in the presence of intestinal disease. We conclude that when solutions are perfused into the small intestine in conditions associated with net fluid secretion, more attention should be paid to predicting the consequent volume changes in the intestine; in practical terms this means care in avoiding excess perfusion rates and ensuring adequate perfusate recovery.

This investigation was supported in part by research grant AM-6908 from the National Institutes of Health, Public Health Service, by grants from the Share Foundation and Mead Johnson and Company, and by a Wellcome research travel grant to D.L.W. It is a pleasure to acknowledge the skilled assistance of Mr Rodney Sandberg. Last, but not least, we are grateful for the enthusiasm and forbearance shown by our volunteer subjects in the face of occasional adversity.

\section{References}

Abbott, W. O., and Miller, T. G. (1936). Intubation studies of the human small intestine. III: A technic for the collection of pure intestinal secretion and for the study of intestinal absorption. J. Amer. med. Ass., 106, 16-18.

Fordtran, J. S. (1969). Segmental perfusion techniques. Gastroenterology, 56, 987-989.

Fordtran, J. S., and Ingelfinger, F. J. (1968). Absorption of water, electrolytes and sugars from the human gut. In Handbook of Physiology, Sect. 6, Alimentary Canal, edited by C. F. Code. Vol. III. Intestinal Absorption, ch. 74, pp. 1457-1490. American Physiology Society, Washington, D.C.

Hepner, G. W., and Hofmann, A. F. (1973). Different effects of free 
and conjugated bile acids and their keto derivatives on $\mathrm{Na}^{+}$, $\mathrm{Ka}^{+}$)-stimulated and $\mathrm{Mg}^{2+}$-ATPase of rat intestinal mucosa. Biochim. biophys. Acta (Amst.), 291, 237-245.

Modigliani, R., and Bernier, J. J. (1971). Absorption of glucose, sodium, and water by the human jejunum studied by intestinal perfusion with a proximal occluding balloon and at variable flow rates. Gut, 12, 184-193.

Phillips, S. F., and Summerskill, W. H. J. (1966). Occlusion of the jejunum for intestinal perfusion in man. Mayo Clin Proc., 41, 224-231.

Pope, J. L., Parkinson, T. M., and Olson, J. A. (1966). Action of bile salts on the metabolism and transport of water-soluble nutrients by perfused rat jejunum in vitro. Biochim. biophys. Acta (Amst.), 130, 218-232.

Russell, R. I., Allan, J. G., Gerskowitch, V. P., and Cochran, K. M. (1973). The effect of conjugated and unconjugated bile acids on water and electrolyte absorption in the human jejunum. Clin. Sci., 45, 301-311.

Schmid, W. C., Phillips, S. F., and Summerskill, W. H. J. (1968). Jejunal trauma following perfusion of the small intestine in nontropical sprue. Gastroenterology, 54, 417-420.

Sladen, G. E., and Dawson, A. M. (1968). An evaluation of perfusion techniques in the study of water and electrolyte absorption in man: the problem of endogenous secretions. Gut, 9, 530-535.

Sladen, G. E., and Dawson, A. M. (1970). Further studies on the perfusion method for measuring intestinal absorption in man: the effects of a proximal occlusive balloon, and a mixing segment. Gut, 11, 947-954.

Whalen, G. E., Harris, J. A., Geenen, J. E., and Soergel, K. H. (1966). Sodium and water absorption from the human small intestine: the accuracy of the perfusion method. Gastroenterology, 51, 975-984.

Wingate, D. L., Phillips, S. F., and Hofmann, A. F. (1973). Effect of glycine-conjugated bile acids with and without lecithin on water and glucose absorption in perfused human jejunum. $J$. clin. Invest., 52, 1230-1236.

Wingate, D. L., Sandberg, R. J., and Phillips, S. F. (1972). A comparison of stable and ${ }^{~ " C} \mathrm{C}$-labelled polyethylene glycol as volume indicators in the human jejunum. Gut, 13, 812-815. 